\title{
A SIMPLe COUPLing OF RENEWAL PROCESSES
}

\author{
T. LINDVALL, ${ }^{*}$ University of Göteborg
}

\begin{abstract}
We use a simple coupling to prove the classical result that the renewal function $U$ of a zero-delayed renewal process satisfies $U(t)-\lambda . t \rightarrow \lambda^{2} \mu_{2} / 2$ as $t \rightarrow \infty$ if the life-length distribution is of non-lattice type and has finite first and second moments $\mu$ and $\mu_{2}$ respectively; $\lambda$ is the renewal intensity, and is equal to $1 / \mu$.
\end{abstract}

COUPLING; RENEWAL FUNCTION

AMS 1991 SUBJECT CLASSIFICATION: PRIMARY 60K05

Let $Y_{1}, Y_{2}, \cdots$ be i.i.d. non-negative random variables with non-lattice distribution $F$, having finite first and second moments $\mu$ and $\mu_{2}$ respectively. To the zero-delayed renewal process $S=\left(S_{n}\right)_{0}^{\infty}$, where $S_{n}=\sum_{1}^{n} Y_{i}, S_{0}=0$, we associate the point process $N: N(B)=$ $\#\left\{n ; S_{n} \in B\right\}$ for $B \in \mathscr{R}_{+}$, and the counting process $\left(N_{t}\right)_{0}^{\infty}: N_{t}=N[0, t]$ for $t \geqq 0$. Let $U(B)=$ $E[N(B)]$ and $U(t)=E\left[N_{t}\right]$. Notice that $U(0) \geqq 1$ always, and $U(0)=1$ if $F(0)=0$. It is rather well known how to use a coupling to prove Blackwell's renewal theorem, which states that

$$
U(t, t+A) \rightarrow \lambda . A \text { as } t \rightarrow \infty
$$

for all $A>0$, cf. Lindvall (1992), p. 73ff.; here $\lambda=1 / \mu$. The classical result

$$
U(t)-\lambda . t \rightarrow \lambda^{2} \mu_{2} / 2 \text { as } t \rightarrow \infty
$$

has, however, not yet been given a coupling proof; the established route is to apply the so-called key renewal theorem to a renewal equation which is solved by $U(t)-\lambda t$, cf. Feller (1966), p. 357. The purpose of this letter is to show how a simple coupling works to prove (2).

Let $Y_{0}^{\prime}$ be independent of $S$ and have density $\lambda .(1-F(y)), y \geqq 0$. We know that if a renewal process with lifelength distribution $F$ has $Y_{0}^{\prime}$ as delay, it is stationary. Let $S^{\prime}=\left(S_{n}^{\prime}\right)_{0}^{\infty}$ be defined by

$$
S_{n}^{\prime}=Y_{0}^{\prime}+S_{n}, \quad n \geqq 0,
$$

and let $N^{\prime}, U^{\prime}$ have obvious meanings. We have

$$
U(t)-\lambda . t=U(t)-U^{\prime}(t)=E\left[N_{t}\right]-E\left[N_{t}^{\prime}\right]=E\left[N\left(t-Y_{0}^{\prime}, t\right]\right] .
$$

But

$$
\boldsymbol{E}\left[N\left(t-Y_{0}^{\prime}, t\right]\right]=\boldsymbol{E}\left[\boldsymbol{E}\left[N\left(t-Y_{0}^{\prime}, t\right] \mid Y_{0}^{\prime}\right]\right]=\boldsymbol{E}\left[U\left(t-Y_{0}^{\prime}, t\right]\right]
$$

Now

$$
U\left(t-Y_{0}^{\prime}, t\right] \rightarrow \lambda . Y_{0}^{\prime} \text { as } t \rightarrow \infty
$$

due to (1). We are allowed to transpose expectation and limit in (4) because of dominated convergence. Indeed,

$$
U\left(t-Y_{0}^{\prime}, t\right] \leqq U\left(Y_{0}^{\prime}\right)
$$

Received 8 July 1992; revision received 24 August 1992.

* Postal address: Department of Mathematics, University of Göteborg, S-41296 Göteborg, Sweden. 
for all $t \geqq 0$, and $E\left[U\left(Y_{0}^{\prime}\right)\right]<\infty$ since $U(s) \leqq C$. $(1+s)$ for some $C>0$ and $E\left[Y_{0}^{\prime}\right]<\infty$. From (3)-(5) we may now deduce (2) since $E\left[Y_{0}^{\prime}\right]=\lambda \mu_{2} / 2$.

The idea of constructing a stationary parallel process by introducing a suitable delay phase as above is of value for the study of regenerative processes in general. The consequences of such coupling will be presented at a later opportunity.

\section{References}

Feller, W. (1966) An Introduction to Probability Theory and its Applications, Vol. II. Wiley, New York.

LindVall, T. (1992) Lectures on the Coupling Method. Wiley, New York. 